\title{
Prevalence and Risk Factors of Hypertension in Hansposa VDC of Sunsari District, Nepal.
}

\section{Dhan Bahadur Shrestha ${ }^{1}$ and Sunil Dhungel ${ }^{2}$}

${ }^{1}$ Medical student; ${ }^{2}$ Department of Physiology; Nepalese Army Institute of Health Sciences, Sanobharyang, Kathmandu, Nepal.

\section{ABSTRACT}

Introduction: Hypertension is defined as a systolic blood pressure (SBP) of 140 millimeter of mercury (mm of $\mathrm{Hg}$ ) or more and a diastolic blood pressure (DBP) of $90 \mathrm{~mm}$ of $\mathrm{Hg}$ or more, or taking antihypertensive medication. Hypertension causes an increased work load on the heart and can cause damage to the blood vessels. The public awareness about hypertension in the villages of Nepal is low and no studies have been conducted earlier to elaborate the risk factors and prevalence of Hypertension in Hansposa village of Nepal. The aim of this study was to identify the prevalence of Hypertension and the risk factors associated with it in this village.

Methods: A cross sectional survey (study) was carried out from September 25, 2014 to October 25, 2014 in order to know the prevalence and risk factor(s) of hypertension among people of Hansposa Village Development Committee (VDC), Sunsari, Nepal. Data were collected from both sexes by asking demographic details, habits like alcohol intake, smoking, exercise and education and examination of blood pressure, weight and height. The association of hypertension with age, sex, education, tobacco, alcohol consumption and body mass index (BMI) were estimated according to WHO standard criteria.

Results: On analysis, the prevalence of hypertension was $37 \%$ [95\% CI=31-42(M: 55.1\%; F: 26.7\%)]. The prevalence of tobacco, alcohol consumption, and overweight/obesity was $31.3 \%$ (including past and present), 36.1\%, and 31.9\% respectively. Further analysis showed that there is significant association between hypertension and age, sex, alcohol consumption and physical inactivity $(P<0.05)$ i.e. there is increasing trend in the prevalence of hypertension with increasing age $\left[\chi^{2}\right.$ (chi square) for linear trend $\left.P=0.000\right]$.

Conclusion: There is high prevalence of hypertension among people of Hansposa VDC; especially isolated diastolic blood pressure and is associated with age, sex, alcohol consumption and physical inactivity.

Keywords: hypertension; isolated diastolic hypertension; obesity; overweight; alcohol; tobacco

\section{INTRODUCTION}

Higher the blood pressure (BP) greater the risk of stroke and lower the life expectancy ${ }^{1,2,3}$. Globally about $50 \%$ of the population is affected with hypertension ${ }^{1}$ and prevalence will increase by $24 \%$ in developed and $80 \%$ in developing countries by $2025^{4}$. Similarly, in low and middle income countries increased prevalence of hypertension has adverse

Correspondence: Dhan Bahadur Shrestha, Dhungedhara, Kathmandu, Nepal. Email: medhan75@gmail.com 
economic impact ${ }^{5}$. Study of Car Nicobar Island of India showed prevalence of 50.5 percent $^{2}$. A study from India predicted two-fold rise in cardiovascular disease (CVD) death in 2020 compared to $1990^{6}$. Hypertension was found to be high in males, diabetic person, unaware population particularly in elderly, obese and alcoholics, smokers and those having high saturated fat and salt intake 2-4,13-18.

As reported by WHO, 27.8\% of Nepalese adults aged 25 years and above are estimated to have Hypertension ${ }^{8}$. In Nepal, the prevalence of hypertension ranged from 18.8-41.8\% with regional variation ${ }^{8}$. Similarly, the prevalence was $33.9 \%$ in Eastern and $22.4 \%$ in central region $^{3,9}$. Hansposa is a typical VDC of Nepal with mixed ethnicity and people from mountainous and Terai region live together. The public awareness about hypertension in this VDC is low and no studies have been conducted earlier to elaborate the risk factors and prevalence of Hypertension. The aim of this study was to identify the prevalence of Hypertension in Hansposa VDC and the risk factors associated with it.

\section{METHODS}

This cross sectional study was carried out in individuals aged over 25 years of Hansposa VDC. The sample size calculation was done according to the total population of the VDC $(27,655)$ and people aged over 25 years $(17,087)^{10}$ with $34 \%$ prevalence of hypertension in rural eastern $\mathrm{Nepal}^{8}$. Assuming a prevalence of $34 \%$ and absolute precision of $5 \%$ with $95 \%$ confidence interval, the required sample size was estimated to be 338 . The participants were selected from different wards as per their availability. Informed consent was taken from all the participants. Required information was taken using structured questionnaire sheet including demographic details, risk factors, examination of blood pressure, height and weight. Blood pressure was measured using sphygmomanometer (DOCTOR, Japan). Three readings were taken over right arm in the sitting position with interval of at least three minute and third one was recorded.The same instrument was used throughout the survey. Weighing machine (KRUPS, DOCTOR BELI RAM \& SONS, Delhi) was used to measure the weight throughout the study period. Height was measured by measuring tape. The weighing machine was standardized each day before starting the survey.

Standard diagnostic criteria for various risk factors and hypertension are described as follows: Body mass index- The adults were classified into different grades of nutritional status as per the international classification of adult into underweight, overweight, and obesity according to $\mathrm{BMI}$ proposed by $\mathrm{WHO}^{1}$. $\left(\mathrm{BMI}<18.50 \mathrm{~kg} / \mathrm{m}^{2}=\right.$ underweight; BMI 18.50 to $24.99=$ normal; $\mathrm{BMI} \geq 25.0$ to 29.99 = overweight; $\mathrm{BMI} \geq 30=$ obese). Hypertension - Individuals with systolic blood pressure (SBP) of $\geq 140 \mathrm{Mm}$ of $\mathrm{Hg}$ and or diastolic pressure (DBP) of $\geq 90 \mathrm{Mm}$ of $\mathrm{Hg}$, those who were already diagnosed and are under medication were considered as hypertensive. $(\mathrm{BP} \leq 120 / 80 \mathrm{~mm}$ of $\mathrm{Hg}=$ normal, BP $>120 / 80$ but $<140 / 90 \mathrm{~mm}$ of $\mathrm{Hg}=$ pre-hypertensive, $\mathrm{BP} \geq 140 / 90$ but $<160 / 100$ $\mathrm{mm}$ of $\mathrm{Hg}=$ Stagel hypertension, $\mathrm{BP} \geq$ $160 / 100 \mathrm{~mm}$ of $\mathrm{Hg}=$ Stage 2 hypertension, $\mathrm{SBP} \geq 160$ but $\mathrm{DBP}<90 \mathrm{mmHg}=$ isolated systolic hypertension, $\mathrm{SBP}<140$ but DBP $\geq$ $90 \mathrm{~mm}$ of $\mathrm{Hg}=$ isolated diastolic hypertension). 
The data obtained were analyzed using the Statistical Package for Social Sciences (SPSS) software (Version 17.0). The overall prevalence of hypertension in relation to various other variables along with 95 per cent confidence interval (CI) was calculated. Bivariate analysis was carried out to find out associations between age, sex, educational status, tobacco consumption, alcohol consumption, BMI with hypertension. The increasing trend in the prevalence of hypertension with increasing age, sex, alcohol consumption and physical inactivity was analyzed by $\chi^{2}$ for linear trend.

\section{RESULTS}

Among the 351 subjects assessed, 130 (37\%) (95\% CI 31-42) were classified as hypertensive. Of the latter, 85 had Stage 1 hypertension, 14 had Stage 2 hypertension, 10 had isolated systolic Hypertension, 21 had isolated diastolic Hypertension (table 1). Among the participants 340 (96.1\%) have checked their BP previously and 101 of 351 (28.8\%) were known case of hypertension due to a medical diagnosis by a doctor. Only 28 of $130(21 \%)$ detected to be hypertensive were on regular treatment currently for hypertension while 24 used to do so previously but not now. However, the control was achieved in one person only.

There was high frequency of alcohol consumption (36.2\%). There is strong correlation between increasing age, sex, alcohol consumption and physical inactivity and hypertension but with overweight/obesity, tobacco consumption and stress and risk of hypertension was found insignificant (table 2).

\section{DISCUSSION}

Present study has documented a high prevalence of hypertension (37\%) and its determinants like overweight/obesity (31.9\%), MJSBH Vol 15 Issue 2 July-Dec 2016
Table 1: Classification of Blood Pressure (BP) in Mm of Hg. HTN: Hypertension

\begin{tabular}{|l|c|c|}
\hline BP classification & Frequency & Percent \\
\hline $\begin{array}{l}\text { Less than or equal to } \\
120 / 080 \text { (Normal) }\end{array}$ & 179 & 51.0 \\
\hline $\begin{array}{l}120 / 080-139 / 089 \\
\text { (Pre-hypertension) }\end{array}$ & 42 & 12.0 \\
\hline $\begin{array}{l}140 / 090-159 / 099 \\
\text { (Stage } 1\end{array}$ & 85 & 24.2 \\
hypertension) & 14 & 4.0 \\
\hline $\begin{array}{l}\text { More than 160/100 } \\
\text { (Stage 2 } \\
\text { hypertension) }\end{array}$ & 10 & 2.8 \\
\hline $\begin{array}{l}\text { Isolated systolic HTN } \\
\begin{array}{l}\text { Isolated diastolic } \\
\text { HTN }\end{array}\end{array}$ & 21 & 6.0 \\
\hline
\end{tabular}

80

60

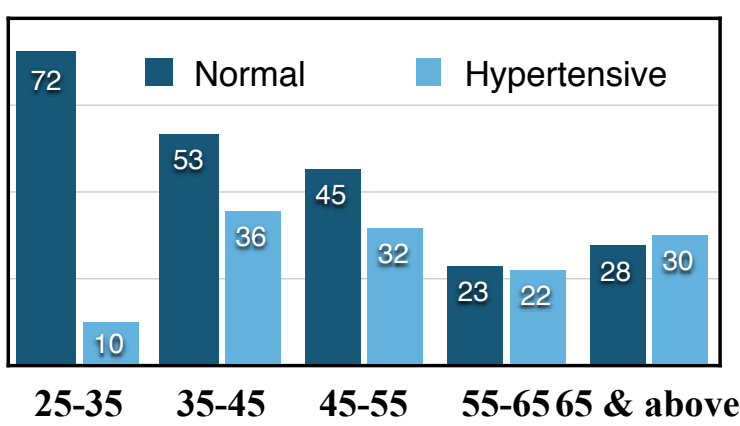

Age group in years

Figure 1: Correlation of hypertension with age.

tobacco smoking (31.3\%) and alcohol consumption (36.2\%), and illiteracy (47.3\%) among the people of Hansposa which is comparable to the previous study of eastern Nepal which showed $33.9 \%$. The sex ratio of study subjects was 127:224(Male: female $=1: 1.76)$ against the census figure $(2070$ B.S., Hansposa VDC Profile) of 1:1.01, this is due to males staying out of the village for work. 
Table 2: Risk factors and their association with hypertension.

\begin{tabular}{|l|l|l|l|l|r|}
\hline Risk factors & & Normal BP (\%) & Hypertensive (\%) & Total (\%) & p-value \\
\hline Alcohol & Yes & $65(18.5)$ & $62(17.6)$ & $127(36.1)$ & 0.000 \\
\hline Smoking & No & $156(44.4)$ & $68(19.3)$ & $224(63.8)$ & \\
\hline BMI & Yes & $65(18.5)$ & $45(12.8)$ & $110(31.3)$ & 0.185 \\
\cline { 2 - 5 } & No & $156(44.4)$ & $85(24.2)$ & $241(68.6)$ & \\
\hline Stressful condition & Supra- & $64(18.2)$ & $48(13.6)$ & $112(31.9)$ & 0.077 \\
\hline Yormal & Normal & $157(44.7)$ & $82(23.3)$ & $239(68.0)$ & \\
\hline Adequate exercise & Yes & $6(1.7)$ & $5(1.4)$ & $11(3.1)$ & 0.385 \\
\hline & No & $215(18.5)$ & $125(35.6)$ & $340(96.8)$ & \\
\hline Education & No & $46(13.1)$ & $55(15.6)$ & $232(66.0)$ & 0.000 \\
\hline & Literate & $126(35.8)$ & $59(16.8)$ & $101(28.7)$ & \\
\hline & Illiterate & $95(27.0)$ & $71(20.2)$ & $185(52.7)$ & 0.023 \\
\hline
\end{tabular}

Though the present study has highlighted on the unknown health problem of the community till the time, it is of preliminary nature with limitations. The lifestyle risk factors like diet, dietary salt, fibre, saturated fat, trans-fat among the Hansposa community were not estimated. It is well known that factors like dietary salt consumption can influence the BP independent of other risk factors ${ }^{2,11}$. Also, though it was the target of the study to get the data of prevalence and risk factors from all 351 subjects whose BP was measured but it could not be achieved because of various socio-cultural beliefs and literacy of the community. All the adult members available in the house were investigated but those who had gone to work or out of the village (predominantly males) for employment opportunities were missed. This is reflected in over representation of older age group and female subjects in the study. But, the fact that prevalence of hypertension adjusted to community based screening for CVD risk MJSBH Vol 15 Issue 2 July-Dec 2016 factor in Eastern Nepal, showing hypertension prevalence of $33.9 \%$ in 2011 proves that findings of present study was not affected by these limitations. Our aim was to choose an appropriate sample size for an expected prevalence of 34 percent with an absolute precision of 5 percent. Since most of the people living in Hansposa share almost same socio-cultural habit, this study has a generalizability value with regard to people living in Nepal. Another limitation was that the diagnosis was made only on three reading of blood pressure on same day and the incomplete follow up data.

It is increasingly been recognized that the poor, marginalized communities are facing the burden of non-communicable diseases in general and hypertension ${ }^{4,5}$ particular. Studies carried out among the Nepalese population have documented hypertension prevalence ranging from 18.8 percent to 41.8 percent $^{8}$. The 
WHO global health observatory 2013, has estimated $27.8 \%$ prevalence of hypertension in Nepalese population of aged 25 and above. In the present study the prevalence of hypertension among population of Hansposa was high. The prevalence documented in the present study is higher than that in Saudi Arabia ${ }^{4}$. The usage of alcohol and tobacco was high among population of Hansposa but only alcohol consumption shows positive correlation with hypertension $(p=0.000)$. It has to be noted that majority consumed locally produced alcoholic beverages. Though the prevalence of overweight/obesity (31.9\%) was also high among population of Hansposa correlation with hypertension was found insignificant $(p=0.077)$. There is also strong correlation between age, sex and physical inactivity and hypertension.

\section{CONCLUSION}

The prevalence of hypertension in Hasposa VDC is $37 \%$ which is relatively high. Also there is significant association between risk factors namely age, sex, alcohol consumption, smoking, physical inactivity and illiteracy.

\section{ACKNOWLEDGEMENT}

We are thankful to Prof. Dr. Lochana Shrestha, Head of the Department, Community Medicine for her help and guidance regarding conduction of study. We acknowledge Prof. Sambhunath Panta and Dr. Bikal Shrestha for their help in statistical function and data analysis and also Mr. Prakashraj Oli and Mr. Barun Babu Aryal for their technical help during data processing.

\section{REFERENCES}

1. Park K. Park's Textbook of preventive and social medicine. 1167 , Prem Nagar, Jabalpur; Bhanot Publisher; 2011:344-48.
2. Manimunda SP, Sugunan AP, Benegal V,Balakrishna N, Rao MV, and Pesala KS. Association of hypertension with risk factors \& hypertension related behavior among the aboriginal Nicobarese tribe living in Car Nicobar Island, India.Indian J Med Res 2011 Mar;133(3): 287-293.

3. Chataut J, Adhikari RK, Sinha NP. Prevalence and risk factors for hypertension in adults living in central development region of Nepal. Kathmandu Univ Med J 2011;33(1)13-8

4. Saeed AA, Al-Hamdan NA, Bahnassy AA, Abdalla AM, Abbas MAF, and Abuzaid LZ. Prevalence, Awareness, Treatment, and Control of Hypertension among Saudi Adult Population: A National Survey.Int J Hypertens 2011;2011:174135. DOI: https://doi.org/10.4061/2011/174135

5. Chockalingam A, Campbell NR, and Fodor J G. Worldwide e pidemic of hypertension,Can J Cardiol 2006 May; 22(7):553-555. DOI: https://doi.org/ 10.1016/S0828-282X(06)70275-6

6. Gupta R.Trends in hypertension epidemiology in India.J Hum Hypertens. 2004 Feb;18(2):73-8. DOI: https://doi.org/ 10.1038/sj.jhh.1001633

7. Kalra S, Narain S, Karki P, Ansari JA, Ranabhat K, Basnet N.Prevalence of Risk Factors for Coronary Artery Disease in the Community in Eastern Nepal - A Pilot Study. J Assoc Physicians India 2011 May; 59:300-1.

8. Dhital SM, Karki A. Dealing with burden of hypertension in Nepal: current status, challenges and health system issues.Regional Health Forum 2013;17(1): 44-52. 
9. Vaidya A, Pathak RP, and Pandey MR. Prevalence of hypertension in Nepalese community triples in 25 years a repeat cross sectional study in rural Kathmandu.Indian Heart J. 2012 Mar;64(2):128-131 DOI: h t t p s : // d o i.org/10.1016/ S0019-4832(12)60045-5

10. VDC profile of Hansposa. 2070 Mangsir.

11. Soudarssanane MB, Karthigeyan M, Stephen S, Sahai A. Key Predictors of High Blood Pressure and Hypertension among Adolescents:A Simple Prescription for Prevention, Indian Journal of Community Medicine. 2006 July - September;31(3): 164-9.

12. Das P, Basu M, Chowdhury K, Mallik S, Dhar G, Biswas A. Observational assessment and correlates to blood pressure of future physicians of Bengal. Niger J Clin Pract 2013;16:433-8. DOI: https://doi.org/ 10.4103/1119-3077.116884

13. Rao CR, Kamath VG, Shetty A, Kamath A. High Blood Pressure Prevalence and Significant Correlates: A Quantitative Analysis from Coastal Karnataka, India.ISRN Preventive Med 2013;2013:574973. DOI: https://doi.org/ $10.5402 / 2013 / 574973$

14. Raza S, Sheikh MA, Hussain MFA, Siddiqui SE, Muhammad R, Qamar S et al. Dietary modification, Body Mass Index (BMI), Blood Pressure (BP) and cardiovascular risk in medical students of a government medical college of Karachi J Pak Med Assoc 2010 Nov;60(11):970-4.

15. Méndez-ChacónE, Santamaría-Ulloa C, and Rosero-Bixby L. Factors associated with hypertension prevalence, unawareness and treatment among Costa Rican elderly. BMC Public Health 2008;8:275.
D O I : h t t p s : / / d o i . o r g / 10.1186/1471-2458-8-275

16. Hathur B, Basavegowda M, Ashok NC. Hypertension: An emerging threat among tribal population of Mysore; JenuKuruba tribe diabetes and hypertension study. Int $\mathbf{J}$ Health Allied Sci 2013;2:270-4. DOI: https://doi.org/10.4103/2278-344X.126748

17. Meshram II, Arlappa N, Balkrishna N, Rao KM, Laxmaiah A, Brahmam GNV. Prevalence of hypertension, its correlates and awareness among adult tribal population of Kerala state, India. J Postgrad Med 2012;58:255-61. DOI: https://doi.org/ 10.4103/0022-3859.105444

18. Todkar SS, GujarathiVV, Tapare VS. Period prevalence and sociodemographic factors of hypertension in rural Maharashtra: A cross-sectional study.Indian J Community Med 2009 Jul;34(3):183-187. D O I : h t t p s : / / d o i . o r g / 10.4103/0970-0218.55269 